\title{
“Cabelo Bom/Ruim ou Bastonete de Queratina?" - Dimensão Estética de uma Controvérsia Étnico-Racial no Ensino de Química no Contexto da Educação Popular
}

\section{"Good/Bad Hair or Keratin Rods?" - Aesthetic Dimension of a Racial Ethnic Controversy in Chemistry Teaching in the Context of Popular Education}

\section{Danilo Seithi Kato Brasil \\ Beatriz Vivian Schneider Felicio Brasil}

O objetivo deste trabalho é investigar a construção de conceitos científicos escolares da disciplina de Química, a partir de uma controvérsia étnico-racial, cujo intuito foi promover, além da relação de ensino-aprendizagem, o engajamento político, visando uma formação crítica sobre o tema em tela. A principal premissa é a de que controvérsias presentes no contexto sociocultural do aprendiz são instrumentos motivadores com potencial para a mobilização do conhecimento científico escolar, bem como dos aspectos identitários relacionados às desigualdades culturais, sociais e econômicas historicamente construídas no Brasil. Os fundamentos teóricos e metodológicos da pesquisa estão apoiados nos pressupostos da perspectiva histórico-cultural. Os sujeitos da investigação eram participantes de um projeto de Educação Popular, e os objetos de análise foram o registro do relato de aula do professor e a entrevista com a aluna que mais se envolveu nas discussões da aula. Os resultados evidenciam o uso dos conteúdos químicos escolares como forma de validar o posicionamento dos estudantes frente à controvérsia proposta, bem como os aspectos éticos e políticos relacionados às questões étnico-raciais, sob o ponto de vista expresso no relato do professor e na entrevista.

Palavras chave: relações étnico-raciais; Educação Popular; ensino e aprendizagem em Química.

This work aims to investigate the construction of scientific school concepts of Chemistry from an ethnic-racial controversy, whose purpose was to promote, in addition to the teaching/learning relationship, the political engagement aimed at a critical formation on the subject. The main premise is that controversies in the student's socio-cultural reality are motivational instruments with potential to promote the mobilization of scientific school knowledge, as well as identity aspects related to the cultural, social, and economic inequalities historically present in Brazil. The theoretical and methodological foundations of this research are based on the assumptions of the cultural-historical perspective. The research subjects are participants in a Popular Education project, and 
the objects of analysis were the record of the teacher's class report and the interview with the student who was most involved in the class discussions. The results demonstrate the use of topics of school chemistry as a way to validate the students' position regarding the proposed controversy, as well as the ethical and political aspects related to racial ethnic issues, from the point of view expressed in the teacher's report and in the interview.

Keywords: racial ethnic relations; Popular Education; teaching and learning of chemistry.

\section{Introdução}

O presente texto deriva do trabalho realizado pelo grupo de pesquisa "Centro de Investigações e Metodologias Educacionais Alternativas Conexão (CIMEAC)", cujos esforços de investigação buscam, dentre outras ações, a compreensão de aspectos relacionados aos processos de ensino-aprendizagem de conceitos científicos escolares. $\mathrm{O}$ estudo ora apresentado se trata de um recorte das pesquisas originadas no grupo, tendo por objetivo investigar a construção desses conceitos na disciplina de Química - ministrada em um projeto de Educação Popular, a partir de uma controvérsia étnicoracial, cujo intuito foi promover, além da relação de ensino-aprendizagem, o engajamento político visando uma formação crítica.

O tema se justifica dadas as africanidades que marcam a história do povo brasileiro e a multiplicidade de etnias que foram expropriadas de seus territórios africanos e submetidas às mais variadas formas de repressões e violências simbólicas pelas práticas colonialistas e escravagistas europeias. Em quase quatrocentos anos de diáspora forjada durante o período Moderno, é possível identificar o legado cultural de forte matriz africana, e, concomitantemente, as condições assimétricas, econômicas e sociais, em relação à parcela afrodescendente da sociedade brasileira.

Ao compreender a origem histórica das desigualdades sociais entre a população negra e branca no Brasil, autores como Munanga e Gomes (2006) discutem a importância dos processos educativos na superação dessa condição subalternizada. Neste sentido, a lei 10.639/03, que prevê e torna obrigatório o trabalho com o ensino de História e Cultura Afro-Brasileira e Africana na educação básica (lei n. 10.639, 2003), em consonância com o Parecer CNE/CP 03/04, que estabeleceu as Diretrizes Curriculares Nacionais para a Educação das Relações Étnico-Raciais e para o Ensino de História e Cultura AfroBrasileira e Africana (Parecer CNE/CP n. 3, 2004), constituiu um avanço na legislação e na democracia, sendo principalmente fruto da mobilização do movimento negro.

A referida lei faz referência à inserção das tradições e cultura Afro-Brasileira em todo o currículo escolar, especialmente nas áreas de Educação Artística, Literatura e História Brasileira, contudo, entende-se que a Ciência, ao longo da história, contribuiu significativamente para o fortalecimento de uma hegemonia cultural branca e eurocêntrica, que salvaguardou o poder colonial a partir da classificação de etnias nãoeuropeias como selvagens e primitivas (Munanga, \& Gomes, 2006). Assim, entendemos que a discussão da lei e diretrizes presentes nos documentos supracitados no contexto 
da Educação em Ciências, em especial no ensino de Química, torna-se relevante para ampliação de uma visão positiva dos povos africanos e da cultura Afro-Brasileira.

Para Verrangia (2014), no âmbito da Educação em Ciências, há ainda uma agenda de pesquisa, no tocante às relações étnico-raciais, a ser contemplada pelos pesquisadores (as) da área. Ele identifica em seu trabalho a escassez de estudos relacionados aos combates às injustiças étnico-raciais a partir do ensino das ciências naturais, bem como mostra que inúmeros estudos deste campo do conhecimento estão organizados de forma acrítica e que ocultam abordagens racistas.

No contexto escolar, disciplinas como Biologia, Física e Química são tradicionalmente organizadas com a finalidade de transmitir conteúdos escolares vinculados a estas disciplinas, deixando de lado aspectos sociais importantes do contexto de racismo estrutural que envolve os sujeitos. Sendo assim, estudos que tragam elementos próprios do processo de ensino-aprendizagem e que não desconsiderem aspectos fortemente presentes em nossa sociedade, como as relações étnico-raciais, se fazem urgentes na busca de uma educação para superação das injustiças raciais.

Sob o contexto do ensino de Ciências/Química em diálogo com as questões históricas e culturais mencionadas, este trabalho trazcomohipótese que a problematização da controvérsia étnico-racial, presente na realidade dos aprendizes participantes deste estudo, seria um instrumento motivador com potencial para desencadear a aprendizagem de conceitos científicos em meio ao debate de temas polêmicos reais e urgentes da sociedade atual; promovendo, assim, com a mediação do professor, a apropriação do conhecimento científico escolar, pautado na discussão crítica da relação étnico-racial, em prol da superação do racismo.

Quando nos referimos à utilização de questões sociais reais como instrumento motivador, referimo-nos a um instrumento metodológico que compõe a atuação do professor em preparar e mediar a atividade de estudo dos alunos, de maneira que uma controvérsia sócio-histórico-cultural real mantenha o motivo da atividade de estudo, contendo a situação-problema que gere a necessidade de apropriação de determinados conceitos científicos escolares para que estes sustentem o posicionamento dos alunos frente à controvérsia.

A atividade de ensino desempenhou o papel de promoção dos diálogos entre conhecimento científico escolar e o conhecimento cotidiano, demonstrados nos objetos de análise deste estudo, quais sejam, o relato de aula do professor e a entrevista com uma das alunas envolvidas no contexto de discussões da aula. As controvérsias aludidas neste trabalho podem ser entendidas como questões sociocientíficas controversas (QSC), na medida em que se apresentam polêmicas, ou seja, dividem a sociedade em posicionamentos antagônicos frente à questão social instaurada, e interrelacionam ciência e sociedade.

Na esteira dos estudos da Educação Popular - a que este trabalho de pesquisa se vincula, considerar a investigação dos próprios impasses sociais e dos possíveis meios de superá-los por intermédio do conhecimento, incluso o científico, implica atribuir sentido 
ao conhecimento a ser apropriado, de modo que sirva aos propósitos de transformação da realidade histórico-cultural dos sujeitos que o mobilizam. Logo, caberia considerar não só as atividades sociais com as quais os sujeitos têm contato, mas também as mediações culturais que as percorrem. Isto é, levar em conta não somente os aspectos culturais presentes nos discursos hegemônicos, mas aqueles próprios dos sujeitos. Dessa forma, entendemos que a concepção de Educação, da Educação em Ciências e do Ensino de Química precisa estar fundamentada em abordagens que contribuam para a transformação da realidade do aprendiz; premissa esta aqui chancelada.

Para buscar as expectativas de uma formação libertadora, partimos da concepção de que o ensino e a aprendizagem devem ser considerados um processo humano, já que produzidos social, histórica e culturalmente. A fim de fazer jus à abordagem apresentada, este trabalho se baseou em uma atividade de ensino diretamente relacionada ao contexto dos aprendizes nela envolvidos, de modo que o aluno se reconhecesse como sujeito ativo, capaz de utilizar o conhecimento a seu favor, tornando-se coautor de seu próprio desenvolvimento.

Sendo assim, buscamos articular as características dos cabelos afro, envolvidas em aspectos de relações étnico-raciais, incluindo suas tensões e contradições históricas, para promover o desenvolvimento da capacidade argumentativa e a apropriação de conceitos químicos prescritos na educação científica. Nessa medida, a problematização do cabelo afro ("cabelo ruim") foi abordada na atividade de estudo em razão da realidade do grupo, o qual, em sua maior parte, era composto por afrodescendentes, como a aluna entrevistada, a qual se mostrou mobilizada pela questão a partir de experiências sociais de sua realidade histórico-cultural.

Com essa contextualização, enunciamos os questionamentos que mobilizaram esta pesquisa: de que maneira ocorre a apropriação de conceitos científicos a partir de uma atividade de estudo constituída por uma questão étnico-racial? Como as dimensões estética, ética e política associadas a esta questão aparecem nesta atividade de estudo? À guisa de respostas, analisamos o discurso emergente do relato da aula pelo professor, bem como a entrevista realizada com uma das alunas. O enfoque analítico se debruçou sobre a manifestação dos conceitos científicos no discurso destes sujeitos que fazem referência ao processo de ensino-aprendizagem vivenciado.

Dessa forma, questionam-se as potencialidades e as limitações das questões sociais e controversas como locus de produção de argumentos, neste caso, científicos, em que o conteúdo químico pode ocupar um lugar de validação do ímpeto persuasivo como parte do processo de tomada de posição do sujeito. É a partir dessa premissa que propusemos a investigação sobre as potencialidades da interface entre a temática racial e o conhecimento químico escolar como forma de promover reflexões sobre essa controvérsia social urgente e emergente do cotidiano do aluno, e a consequente apropriação de conceitos provenientes da ciência. 


\section{Referencial teórico}

Este trabalho fundamenta suas motivações à luz da teorização empreendida pela Educação Popular e pela Teoria da Atividade sócio-cultural-histórica.

A Educação Popular, movimento social que surge como prática educativa de grupos sociais desfavorecidos por fatores econômicos e políticos, pretende, em sua abordagem, investigar impasses sociais, culturais, políticos e econômicos dos sujeitos, para que, por meio da tomada de consciência sobre os problemas de sua realidade, possam transformá-la, apropriando-se do conhecimento como instrumento libertador. (Freire, 1967; Gadotti, 2012; Grossi, 1984; Jara, 2010; Narita, 2014).

Pelo viés da Educação Popular, a transformação da realidade do sujeito por ele mesmo acarreta implicações em seu desenvolvimento cognitivo, imbricado nas suas necessidades sócio-histórico-culturais, o que torna insuficiente ter apenas o conhecimento científico escolarizado/formal como ferramenta libertadora.

A partir desta concepção de Educação, consideramos que os processos de formação do sujeito, seja em ambiente formal, não formal, ou informal, são processos humanos, não ocorrendo individualmente, sem a mediação de outrem. Tampouco, a transformação libertadora do sujeito ocorrerá em um processo fragmentado, tipicamente escolar, em que a realidade social e os conceitos científicos escolares são paulatinamente abordados de forma desvinculada para posteriormente se relacionarem em exemplificações pontuais. Consideramos que esta concepção corrobora a perspectiva da Teoria da Atividade (Leontiev, 1978, 1983; Vigotski, 2007, 2009) em relação aos processos de apropriação de conhecimento pelo homem, e é na ordem desta abordagem que fundamentamos os subsídios teóricos deste trabalho.

Considerando, portanto, a Teoria da Atividade em consonância com as problematizações levantadas pela Educação Popular, conseguimos delimitar a pesquisa em discussão por meio de uma atividade de estudo, aqui compreendida como QSC. De acordo com a Teoria da Atividade, a atividade de estudo diverge de "atividade", pois esta designa um trabalho qualquer realizado pelo aluno; enquanto aquela dialoga com o desenvolvimento psicológico do aprendiz. A atividade de estudo não tem um fim em si mesma, mas cria uma condição crucial para o desenvolvimento intelectual, moral e motivacional do aluno, de modo a desenvolver autonomia pela busca de conhecimento e mudança de atitude social e pessoal, resultando em influências para o desenvolvimento de sua personalidade. (Davidov, \& Marcova, 1987).

O desenvolvimento das QSC tem origem na Educação em Ciências - Ciência, Tecnologia e Sociedade (CTS), conforme atestam Aikenhead (1994) e Pedretti (2003). As QSC, ainda, corroboram o movimento da Educação Popular quando propõem uma abordagem articulada à realidade dos alunos sob uma perspectiva humanística. (Santos, 2007).

As QSC, de acordo com Sadler e colaboradores (2006), são polêmicas reais que contextualizam conteúdos tradicionais oriundos da ciência em relação às considerações éticas, morais e valorativas dos temas sociais, o que nos aponta expectativas de 
aprendizagem para além dos conteúdos disciplinares, pautadas no interesse dos alunos em buscar o entendimento dos conhecimentos científicos específicos, a fim de entender o problema real, e assim efetivar um pensamento crítico, com vistas a uma formação humana de caráter libertador.

Pensando nisso, é necessário considerar o fato de o ensino de Química ${ }^{1}$ abordar objetos de estudo invisíveis ao olho humano, e, portanto, representados por meio de modelos científicos (Gilbert, Boulter, \& Elmer, 2000), teorias e conceitos, que buscam explicar os fenômenos naturais por meio do comportamento da matéria. Wartha e Rezende (2011) trazem um panorama das discussões da literatura do Ensino de Química sobre as dificuldades de aprendizagem identificadas em alunos e sua relação com a desconexão entre os níveis representacionais dos conceitos químicos (macroscópico, simbólico, submicroscópico e variações), bem como as diferentes proposições dos autores sobre como considerar tais níveis representacionais no processo de ensinoaprendizagem. No caso deste trabalho, o nível macroscópico, o qual tomamos como ponto de partida, refere-se a um fenômeno natural visível que suscita uma controvérsia étnico-racial recorrente nos círculos sócio-histórico-culturais dos nossos alunos.

Um dos aspectos a serem considerados em relação aos conceitos submicroscópicos é a demanda por habilidade de abstração para a compreensão de conceitos e teorias, bem como para a compreensão de modelos explicativos. A abstração exigida para a formação de conceitos não deve ser o fim do processo de construção de conhecimento, mas sim o elo intermediário de um contínuo movimento de redução do concreto imediato ao abstrato e de ascensão ao concreto real, complexificado. Redução no sentido de isolar elementos do concreto imediato, sensório, para que sejam complexificados por meio da atividade de práxis no momento de estudo dos conceitos abstratos. Ascensão no sentido de retornar a análise do concreto real agora complexificado pelos conceitos abstratos. (Camillo, \& Mattos, 2014). Acreditamos que questões sociais reais contribuam como ponto de partida e de chegada para este movimento de redução do concreto imediato, abstração e ascensão ao concreto complexificado, mantendo a motivação da atividade de estudo, justamente por trazerem aspectos reais e controversos que fazem sentido para o aluno por pertencerem a sua realidade imediata, sócio-histórica-cultural.

A perspectiva intercultural e dialógica de ensino e aprendizagem em Educação Científica aqui adotada compreende a ciência enquanto cultura estrangeira em cruzamento com as demais culturas do estudante (Aikenhead, 2009). Tais saberes destas diferentes culturas devem coexistir, sem que um substitua o outro, e serem utilizados de acordo com a pertinência dos contextos em que são discutidos (Aikenhead, 2009; Candela, 1999; Driver, Asoko, Leach, Mortimer, \& Scott, 1999). Esses princípios fundamentam uma ação docente condizente com os ideais da Educação Popular, que visa ao não silenciamento das culturas historicamente marginalizadas em um cenário contemporâneo de grandes assimetrias econômicas e sociais. Assim, aspectos culturais,

1 Assim como a Física e a Biologia, porém mais recorrente no ensino e aprendizagem da Física e da Química, objetos de estudo na escala submicroscópica. 
tanto da ciência quanto dos saberes cotidianos, são postos em interação com a finalidade de diálogo, apropriação e significação para a tomada de posição dos aprendizes.

Neste viés, que abarca uma concepção de educação de caráter humano, o sujeito não deve ser apartado da apropriação do conhecimento produzido historicamente pela humanidade; ao contrário: deve ser incluído como sujeito ativo, e não alijado de sua própria história e cultura. Ao levar em conta a realidade dos sujeitos desta pesquisa, devemos considerar a realidade de exclusão social característica dos alunos frequentadores de cursinhos populares ${ }^{2}$. Estes são em sua maioria egressos do Ensino Médio da rede pública, sem condições financeiras para custear estudos para além deste nível, desembocando no mercado de trabalho dos contratos temporários e subempregos, e que encontram em projetos de Educação Popular uma chance de melhorar a condição de vida ingressando em uma universidade pública. A fim de atender a este público, creditamos a Educação Popular o caráter de busca pela práxis educativa, já que, como perspectiva educacional (teoria) e como movimento social (prática), permite aos professores pesquisadores o estudo, a aplicação e a análise de teorias psico-educacionais, de linguagem e de perspectivas da Educação em Ciências que venham convergir para a promoção da transformação da realidade do sujeito aprendiz.

\section{Procedimentos metodológicos}

A atividade de estudo foi realizada com alunos de um curso pré-vestibular popular, noturno, composto por integrantes e egressos do Ensino Médio, cuja frequência do dia contou com a presença de 10 discentes. Os autores do presente estudo atuaram, durante o ano de 2016, como professores no referido curso. Importante salientar que o grupo, seguindo pressupostos da Educação Popular, estava organizado de forma que todos os professores participavam das atividades de planejamento e organização curriculares. Assim, ambos os autores deste artigo estiveram, na ocasião, envolvidos com as ações de planejamento, execução e avaliação da aula ${ }^{3}$.

O currículo, organizado de forma participativa entre professores e alunos, partia dos pressupostos Freireanos de investigação temática para organização do trabalho coletivo. O grupo constituía oito módulos com temas emergentes das realidades e das vivências dos participantes do curso. Já no processo seletivo para o ingresso no grupo, era aplicado um questionário com questões abertas, com uma fase preliminar diagnóstica, com intuito de conhecer a realidade dos sujeitos pretendentes a uma vaga.

Por este motivo já era de conhecimento algumas das contradições envolvendo a temática étnico-racial, em especial, a questão do cabelo para alguns alunos (as). A partir de uma discussão no módulo "Energia: como as diferentes manifestações da

2 Cursinhos populares ou comunitários são caracterizados como um espaço não formal de ensino, sem fins lucrativos, em que os professores são voluntários e visam à democratização do acesso ao Ensino Superior de qualidade (Kato, 2011).

3 O grupo de professores permanece atuante por meio de ações como editoração de revistas e divulgação de resultados. Ainda, planejamos ações pontuais em espaços públicos (como praças), ou reuniões em residências dos integrantes dos grupos. 
energia se relacionam com os sistemas econômicos, políticos, sociais e ambientais e perspectivas para o século XXI", em que a discussão sobre ciência e tecnologia ganharam força argumentativa para os alunos, é que foi pensada uma relação deste discurso de autoridade com a dimensão estética de uma questão étnico-racial. A proposta foi sendo construída a partir destes elementos anteriores e foi realizada meses depois no módulo "Direitos Humanos e identidades culturais".

A atividade, em um primeiro momento, propôs aos alunos concordarem ou não com o seguinte dizer escrito na lousa pelo professor: "O cabelo dela é ruim, mas hoje tem chapinha, formol, tem ciência e tecnologia que pode fazer com que o cabelo fique bom."

$\mathrm{O}$ enunciado em questão foi captado pelo professor em falas cotidianas dos próprios alunos, e levado para posicionamento da classe com o intuito de motivála à discussão. $\mathrm{O}$ docente, então, pediu a ela que levantasse algumas hipóteses para problematizar o dito. Estas, neste momento, ainda pertenciam ao concreto imediato, estabelecendo-se como controvérsia não pelo fato de ser um enunciado racista ou não, mas sim pela origem do racismo.

O professor, buscando sistematizar a discussão, dividiu os alunos em dois grupos, cujos integrantes haviam se posicionado de forma semelhante durante a fase inicial. $\mathrm{O}$ primeiro foi formado por àqueles que defendiam que as ideias expressas no enunciado tinham uma origem estritamente social, concordando que um tipo de cabelo era mais bonito do que outro. Por isso, foram orientados a estudar questões relacionadas à história do Brasil. O segundo grupo, por sua vez, pressupunha que uma diferença biológica devia ser investigada para verificar o racismo, pois defendiam que as diferenças eram naturais e que a beleza era relativa. Após orientações do mediador, que indicou aspectos envolvendo a composição química do cabelo e orientou os alunos na busca de conteúdos químicos nos índices dos livros didáticos ${ }^{4}$ disponíveis em sala de aula, a fim de que fundamentassem os argumentos a serem defendidos, o grupo estudou a estrutura molecular de proteínas, pois identificaram que a queratina capilar era uma proteína, para, posteriormente, se posicionarem novamente em relação ao enunciado. Após este momento, os alunos foram convidados a socializar suas conclusões.

As discussões foram iniciadas em pequenos grupos. Um explicava para o outro como entenderam as informações no livro texto. Em seguida, o grupo elaborou esquemas para articular à proposta de cabelo bom/ruim, mostrados ao mediador. Este somente comentava a leitura sobre os significados atribuídos aos conceitos científicos escolares, dialogando com os estudantes sem definir por eles. Por fim, o grupo foi à lousa, desenhou o esquema e os tópicos relacionados. A aluna negra liderou (por decisão deles) a explicação. O outro grupo fazia perguntas, caso não entendessem algo, mas retomavam a ideia do racismo. O mediador podia interferir, mas a ideia dos professores é sempre fomentar a controvérsia, a fundamentação e a complexificação dos argumentos científicos.

4 Organizamos uma biblioteca com doações para que os alunos tivessem material disponível em cada atividade. Alguns usavam smartphones para buscar uma informação ou outra. Mas as mediações com relação à busca de conteúdo (nos livros e sumários) fazem parte de nossa metodologia. 
Logo após a aplicação da atividade de estudo, o professor da turma relatou essa experiência a outros professores do cursinho, deixando em evidência suas observações a respeito da reflexão dos alunos sobre a apropriação dos conceitos químicos. Tal relato foi gravado em áudio e analisado a partir das perspectivas histórico-culturais da Atividade (Leontiev, 1978, 1983; Vigotski, 2007, 2009) relacionadas à aproximação entre os conceitos científicos e cotidianos, e também à apropriação de conceitos químicos com a mediação da atividade pelo professor.

Neste artigo discutimos excertos do relato do professor referente ao grupo que buscava fundamentação na química para superação do racismo. A fim de consubstanciar o relato docente, realizamos também uma entrevista com uma aluna afrodescendente, que mais se destacou na discussão proposta. Este instrumento, uma vez que possibilita a apreensão da realidade do outro por meio dos discursos (Fraser, \& Gondim, 2004), permitiu a construção de dados complementares para análise a respeito do reconhecimento de motivo, necessidade, objeto, ações e objetivo da atividade de estudo proposta, bem como de aspectos para a formação de conceitos químicos por meio da análise da significação, apropriação e generalização.

O questionário para a entrevista contou com o seguinte roteiro ${ }^{5}$ :

1. O que mais te marcou nesta aula?

2. A afirmação "seu cabelo é ruim! Mas a ciência e tecnologia podem resolver seu problema por meio da química" mobilizou você de que forma? O que te causou?

3. Como os conhecimentos químicos contribuíram para fundamentar seu argumento?

4. O que você recorda em relação aos conteúdos de Química que ajudaram a justificar o seu posicionamento perante a questão "cabelo ruim/cabelo bom"?

5. Você considera esta aula uma aula de Química? Justifique o motivo.

6. Você chegou a usar alguns dos conceitos estudados em outra ocasião da sua vida? Se sim, pode nos contar como foi?

7. Ao pensar a metodologia educacional utilizada neste projeto de Educação Popular, como acha que ele colaborou para mudar a sua forma de estudar/ pensar?

8. Quais princípios deste projeto você levou para sua carreira acadêmica?

9. Este é um espaço para que você coloque mais alguma informação desta aula e que não perguntamos neste roteiro. Use se for necessário para complementar as outras questões.

A próxima seção irá se dedicar, assim, à análise dos dados alcançados com a participação dos sujeitos colaboradores deste estudo.

5 Antes do início da entrevista, os pesquisadores explicitaram os objetivos da investigação, bem como os aspectos éticos envolvendo a pesquisa, e solicitaram a leitura e assinatura do termo livre esclarecido, documento no qual a aluna autoriza o uso da entrevista para este estudo. O mesmo procedimento foi realizado para a utilização do relato do professor, respeitando os pressupostos éticos da pesquisa envolvendo seres humanos. 


\section{Resultados e Discussão}

Primeiramente apresentaremos resultados e discussões referentes aos relatos do professor ministrante da aula e, posteriormente, os referentes à entrevista realizada com a aluna que mais se envolveu com a atividade proposta.

\section{Relatos do professor}

Segundo o relato do professor, o enunciado escrito na lousa, antes do início da aula, provocou incômodo nas alunas que chegaram à classe. De acordo com o professor, os primeiros posicionamentos foram, como esperado, pautados apenas em noções triviais e automáticas do cotidiano. As falas, lembradas pelo professor, referentes a este momento da aula, foram curtas e restritas às impressões mais gerais sobre o tema:" $A h$, eu acho que tem uma questão de preconceito, porque cabelo ruim, cabelo bom..."; Poxa, realmente, se você tem um cabelo estranho, de bermuda, a noite, a polícia vai te parar, né. Então não é questão de bom ou ruim, mas é estranho."

Percebeu-se que tanto a primeira observação, que levantou a questão do preconceito, quanto a segunda são manifestações da esfera social com a qual os estudantes se relacionam, pertencentes à realidade objetiva, e que ainda não se ajustam à linguagem científica escolar. Ou seja, se não houvesse a mediação dialógica do professor em direção aos conceitos que se pretendia estudar, os alunos não fariam sozinhos esse caminho, e as discussões permaneceriam na realidade objetiva.

No momento da aula, o professor questionou se a composição química dos cabelos justificaria o julgamento de sua qualidade. Os alunos mostraram desconhecimento sobre isso, e o professor provocou o conflito defendendo o seguinte argumento: "seria possível que as moléculas que constituem o cabelo explicassem que realmente ela tem cabelo ruim?" Em seu relato, o professor mostrou que este era o ponto chave para o engajamento dos estudantes frente à controvérsia, pois ficaram mobilizados a investigar sobre a constituição química do cabelo. Este momento representa a "redução temática" ${ }^{6}$ que promoveu a inserção do conhecimento químico na pauta da discussão social mais ampla, momento no qual se esperava que os alunos participassem da atividade de estudo, motivados pela necessidade de saber se a composição química dos cabelos justifica ou não a afirmação inicial, para, depois, se posicionarem diante dela.

Posteriormente, o relato do professor apresentou ênfase no engajamento dos alunos em procurar informações sobre a composição do cabelo e relacioná-las com as estruturas moleculares das proteínas, a partir da sua orientação sobre o assunto e

6 Fazemos referência à fase do processo de investigação temática Freiriano (Freire, 1987) iniciada a partir das análises das decodificações e do estudo, sistemático e interdisciplinar, dos achados. Neste caso, apesar de não seguirmos os passos da investigação temática nesta atividade específica, é importante ressaltar que o projeto de Educação Popular, da qual a atividade e os sujeitos fazem parte, foi estruturado integralmente, tanto no plano curricular quanto nas práticas, segundo preceitos da abordagem Freireana de Educação, associando as diferentes fases da investigação em diferentes aulas do curso. A partir deste termo, representamos a fase em que ocorreu a seleção de conceitos científicos escolarizados envolvidos na questão central da atividade. 
de como acessar este conteúdo nos livros didáticos, disponibilizados no momento de busca das informações. Os alunos, organizados em pequenos grupos, puderam discutir a possibilidade do uso de conceitos químicos para elaborar uma resposta ao enunciado que desencadeou a atividade.

Em seguida, no momento de socialização das informações entre os grupos, no qual era esperado que os alunos utilizassem conceitos químicos para se posicionarem em relação à problemática presente na expressão "cabelo ruim", o professor relatou que chamou sua atenção um dos grupos ter começado a expor suas conclusões com a seguinte afirmação: "Cabelo ruim não existe, quimicamente falando."

Importante salientar que a aluna que elaborou a afirmação anterior é afrodescendente, e durante o trabalho mostrou-se motivada com a questão, não pelo dizer em si, mas por não conseguir pensar em um argumento científico que o desabonasse. Após a mediação do professor e compreensão de aspectos moleculares da queratina, o grupo de alunos elaborou a justificativa para a afirmação a partir dos conceitos químicos estudados, o que foi relatado pelo professor da seguinte maneira:

Os alunos falaram de ácido carboxílico, falaram de grupo amina, pontes de sulfeto pra explicar o cabelo crespo, falaram do polímero biológico, mostraram como o formol, a chapinha desmanchava a estrutura quaternária da proteína, mostraram que com a chapinha isso volta porque é um fenômeno que depende da temperatura, falaram que quando é com formol você tem uma alteração química das reações peptídicas.

Observa-se neste relato uma variedade de conceitos do campo da Química orgânica, os quais o professor afirmou terem sido utilizados pelos alunos para defender a tese de que cabelo ruim não existe. Não é nossa intenção analisar, em profundidade, a qualidade e as articulações dos argumentos no discurso dos alunos, mas a presença de elementos da linguagem científica escolar, presenciada e relatada pelo professor. Ao defenderem sua afirmação a partir de conceitos químicos, utilizaram-nos como instrumento para a resolução de um problema (Vigotski, 2009), neste caso específico, para o enfrentamento de uma controvérsia social. A fim de que isso acontecesse, houve a necessidade de apropriação desses conceitos e sua utilização para o posicionamento dos alunos frente a uma controvérsia pertencente ao seu cotidiano. Logo, houve a complexificação dos conceitos e da realidade concreta.

A partir do relato completo da aula, observou-se que a presença destes conceitos, no discurso dos alunos, percorreu o movimento discutido por Camillo e Mattos (2014) graças à mediação do professor durante toda a atividade de estudo, a qual considerou, em um primeiro momento, as impressões e justificativas mais superficiais que pairavam sobre percepções pessoais e sensoriais do concreto imediato, para, em um segundo momento, orientá-los rumo a um contato com conceitos abstratos que passaram a estudar e entender. Em um terceiro momento, os alunos foram guiados a explicitar, para todos da sala de aula, o uso dos conceitos estudados dentro da controvérsia social, que, assim como os conceitos, é complexificada.

Vale aqui destacar o depoimento da aluna entrevistada em relação ao seu 
envolvimento com a atividade de estudo:

Eu to bastante envolvida porque eu era essa pessoa que..., eu tinha vergonha do meu cabelo, eu tentava esconder o meu cabelo com chapinha, com formol, o que fosse, e eu achava que meu cabelo era ruim. E hoje, com as coisas que eu vejo aqui no (nome do cursinho), eu vejo que é a minha ancestralidade, a minha raiz. E eu sou muito feliz com meu cabelo. Isso fez muito bem pra minha identidade, pra minha vaidade.

Isso mostra que a controvérsia social é pessoal para a aluna. $\mathrm{O}$ processo de significação, que constituiu aproximações entre os sentidos pessoais e os significados dos conceitos químicos, mostrou-se fundamental para o estabelecimento da controvérsia para um grupo social. O vínculo entre a questão social real colocada é mais profundo, e a manifestação dos significados é mais latente quando há o encontro entre as experiências sociais e a demanda pela superação de conflitos. Assim, os resultados evidenciam que o uso das QSC não é eficiente, de forma padrão e genérica, para qualquer realidade. É necessária a mediação do professor para que se estabeleça a controvérsia a partir das características peculiares dos interlocutores.

\section{Entrevista com aluna}

Esta entrevista foi realizada aproximadamente um ano após a aula, virtualmente, por meio de mídia social WhatsApp, já que a entrevistada se encontrava em outra cidade, onde passou a cursar Psicologia. Organizamos os dados de forma a contemplar as temáticas emergentes da entrevista. Em outras palavras, após a análise do material, identificamos movimentos discursivos que permitiram a sistematização dos dados de forma a contemplar nossas análises frente ao referencial teórico adotado. Como a entrevista foi realizada a partir de texto escrito, selecionamos e apresentamos os trechos exatamente como escritos pela aluna.

\section{A mobilização do motivo: a dimensão estética da questão étnico-racial para a consolidação da atividade}

A entrevista foi iniciada com a retomada da aula. Após a contextualização para situar a entrevistada, ela foi questionada sobre qual aspecto mais a havia marcado na aula. $\mathrm{O}$ enunciado produzido pela estudante evidenciou o processo de mobilização do motivo da atividade:

O que marcou bastante para mim desta aula foi conseguir argumentos com embasamento científico para rejeitar a afirmação de que existe um tipo de cabelo ruim. No momento em que a aula aconteceu eu estava vivenciando a experiência da transição capilar (parando de utilizar químicas de transformação no meu cabelo), e vários amigos e familiares me questionavam sobre o que de eu querer o meu cabelo "duro". E eu só conseguia dizer o porquê de eu não querer mais utilizar químicas, mas não conseguia desmontar a ideia de um cabelo ruim/duro nas pessoas. Apesar de antes da aula já ter ido pesquisar sobre (justamente para entender e tentar fazer com que outras pessoas entendam também), mas a aula esclareceu muitas lacunas que ainda estavam na minha 
cabeça sobre o assunto. Sobre o porquê.

De acordo com Leontiev (1978), as atividades são processos psicológicos que satisfazem uma necessidade específica do sujeito, dirigidas, como um todo, a um objeto, que coincida com o objetivo que estimula o sujeito a executar as ações que compõem a atividade - o motivo que deriva da necessidade. Envolvem emoções e sentimentos. $\mathrm{O}$ autor distingue ação e atividade, pois o ato ou ação é um processo cujo objetivo não coincide com o motivo da atividade, mas reside na atividade. Nas palavras de Leontiev, "o objetivo de uma ação, por si mesma, não estimula a agir. Para que a ação surja e seja executada, é necessário que seu objetivo apareça para o sujeito, em sua relação com o motivo da atividade da qual ele faz parte" (p. 69). Assim, o objeto de uma ação é seu alvo direto, não o motivo da atividade, mas mantém certa relação com este.

No entanto, uma ação pode se transformar em uma atividade na medida em que o motivo desta é transferido para o objetivo da ação. Ou o objetivo da ação se torna um motivo para o sujeito, transformando a ação em uma atividade de práxis. Segundo Leontiev (1978, p. 69), "Esta é a maneira pela qual surgem todas as atividades e novas relações com a realidade".

No caso da aluna, podemos observar que o sistema de atividades vivido por ela trazia a necessidade de superação do preconceito sofrido, o que envolve sentimentos e emoções pessoais, e coincide com a precisão de se posicionar perante a questão social controversa de caráter étnico-racial colocada em aula. Essa necessidade, em seu cotidiano, gera o motivo para várias ações - como a busca por novo tratamento capilar, por justificativas para decisão de parar de alisar o cabelo e por conhecimento científico. $\mathrm{Na}$ medida em que a aluna executa estas ações, elas se transformam em atividades, pois o motivo da atividade de posicionamento perante o racismo é transferido para as ações, dando sentido pessoal a elas. Assim, a ação de busca por conhecimento científico é motivada não só pela justificativa de seu posicionamento em relação ao modo de uso do cabelo (objetivo da ação), mas pela própria superação do preconceito, o que transforma a ação em atividade. Se a atividade de busca por conhecimento científico demanda ações como entender códigos e linguagens da Química, estas ações podem se transformar em atividade de práxis se o motivo da atividade for transferido a elas, o que é possível com a mediação do professor e dos colegas de aula. No caso da aluna, isto se concretiza, mas sabemos que, no caso de alunos que não compartilham da mesma necessidade e motivo, o sentido é diferente e o efeito da atividade também. No entanto, oportuniza a compreensão sobre como seu semelhante se sente frente a preconceitos.

Há uma diferença expressa pela aluna entre a atividade de busca pelo conhecimento científico, quando realizado por conta própria; e a mesma atividade, quando realizada em aula em relação à objetivação/concretização da atividade.

Ao expressar "Apesar de antes da aula já ter ido pesquisar sobre (justamente para entender e tentar fazer com que outras pessoas entendam também), mas a aula esclareceu muitas lacunas que ainda estavam na minha cabeça sobre o assunto", percebemos que a concretização dessa atividade se deu, efetivamente, em aula. 
Atribuímos esta concretização ao planejamento e mediação da atividade de estudo pelo professor, que direcionou, de forma intencional, questionamentos que contribuíram para o entendimento da composição química dos cabelos e desvelaram a ideia de cabelo ruim. Sem a mediação intencional, os alunos poderiam permanecer nas opiniões de ordem restrita à experiência imediata, ou perder tempo em fontes de informação que não satisfizessem a necessidade. De acordo com o referencial teórico adotado, permanecer nas opiniões pessoais impossibilita a aproximação do sentido pessoal ao significado do objeto, o qual se refere ao conhecimento produzido pela humanidade em relação ao referido objeto. (Leontiev, 1983). Ressaltamos, aqui, que o processo de significação, como função social da escolarização e, portanto, do ensino de ciências, é emancipador e comprometido com a superação do racismo.

$\mathrm{O}$ enunciado "O que marcou bastante para mim desta aula foi conseguir argumentos com embasamento científico para rejeitar a afirmação de que existe um tipo de cabelo ruim" mostrou que o objetivo de ensino-aprendizagem foi cumprido. Ou seja, a objetivação/concretização foi alcançada pelo sujeito. O objetivo/motivo da atividade estava diretamente ligado ao objeto de ensino/estudo: rejeitar a afirmação de que existe um tipo de cabelo ruim. $\mathrm{O}$ objeto da questão foram os conceitos químicos que deram embasamento científico aos argumentos. Para Leontiev, na atividade de estudo, a necessidade diretamente relacionada ao objeto de estudo gera o motivo da ação, transformando-a em atividade. Como já observamos, a atividade de ensinoaprendizagem proposta na aula possui elementos coincidentes com as atividades pelas quais a aluna passava em sua vida.

Isso nos mostra que a abordagem de temas reais recorrentes no cotidiano dos alunos traz sentido a conceitos abstratos produzidos no seio de outra cultura, a científica. Neste caso, a objetivação da atividade só é alcançada graças à mediação do professor, ou seja, a QSC/questão étnico-racial por si só não desencadearia a atividade de estudo dos conceitos químicos sem a atuação do professor.

Continuando a entrevista, a aluna foi inquirida sobre o dizer colocado no quadro pelo professor: "O cabelo dela é ruim, mas hoje tem chapinha, formol, tem ciência e tecnologia que pode fazer com que o cabelo fique bom." O entrevistador a provocou com intenção de saber mais sobre como ela se sentiu e em que medida os aspectos afetivos estavam associados ao motivo da atividade:

Essa frase eu confesso que até mesmo nesse momento mexe demais com alguns sentimentos que tenho dentro de mim. Ela me causa uma espécie de angústia. Pois desde de muito cedo, eu sempre a ouvi. Minha família, uma família de negros, de mulheres de cabelos crespos, era um dos veículos para essas frases. E eu sempre vi minha mãe e minhas tias com seus cabelos alisados ou com apliques, dizendo "finalmente estou bonita, e sem cabelo duro" e zombando de pessoas que não davam um jeito de domar o seu cabelo crespo, e isso me doía muito. Até que com 7 anos após muita zoação na escola, muito cabelo mal cuidado (pois minha mãe não sabia lidar com um cabelo tão "rebelde"), eu fui pela primeira vez em um salão fazer um alisamento. Me senti muito bem. E desde então, minha mãe sempre me levava para fazer esse procedimento. Porém 
eu fui crescendo, e na pré adolescência percebi que não estava satisfeita. Meu cabelo não era liso, lisinho. A raiz estava sempre à mostra, sempre crespa. Lembro do dia que com uns 13 anos falei para minha mãe que tinha raiva dela por ela ter me feito com aquele cabelo duro, e que minha vontade era comer formol pra ver se ele crescia liso. Passei muita humilhação e sofri demais na escola por conta do meu cabelo. Fora as provações de não entrar em piscinas, e etc.

Esta resposta nos mostra que o tema abordado em aula teve sentido para a aluna, e também nos sensibiliza enquanto educadores, pois, por mais que saibamos da recorrência do tema na sociedade, não temos noção de como isso afeta os sujeitos, e de como pode ser importante tocar em assuntos como este a fim de auxiliá-los em sua tomada de consciência, transformação e libertação. Percebemos que as características do cabelo afro são marcadas de forma pejorativa desde uma perspectiva ontológica do sujeito, estendendo-se historicamente para seus descendentes, de tal maneira que os leva a negar parte de sua identidade, em nome da inclusão em uma sociedade e cultura hegemônica que os oprime. Diante disso, entendemos que se torna urgente a busca por temas reais que possam ser complexificados e ressignificados, por meio de atividades de práxis com a ajuda do conhecimento científico, a fim de que este atenda também às necessidades do aprendiz, não apenas em caráter propedêutico, visando questões avaliativas, como no caso dos vestibulares.

A escolha, portanto, de uma atividade de estudo cujos elementos coincidam com a realidade do aluno pode fazer toda diferença para a significação de conceitos abordados em sala de aula. Sabemos que a escolha de determinada atividade de estudo não atinge a todos os alunos igualmente, mas isso pode ser trabalhado, focando-se em diferentes casos ao longo do tempo para que a diversidade da turma seja atendida.

\section{Processos de significação a partir do movimento persuasivo: aprendizagem como posicionamento político}

Após a mobilização do motivo para a atividade, os dados da entrevista evidenciaram ainda mais os processos de significação dos conceitos químicos no intuito de sustentar o posicionamento discursivo da aluna. O entrevistador perguntou como o conhecimento químico a auxiliou em seu posicionamento frente ao dizer racista. $\mathrm{E}$ pediu para que ela explicitasse como este conhecimento contribuiu para fundamentar seu argumento.

Como relatado, eu estava vivenciando a transição capilar no período em que ocorreu a aula. E confesso não ter utilizado o argumento químico de fato explicadinho como foi visto em aula. Eu dava umas adaptadas nele para o senso comum, já que os comentários que eu recebia sobre meu cabelo eram todos muitos grosseiros, e as pessoas não estavam nem um pouco preocupadas em entender o que realmente é um cabelo crespo. Mas enfim, para exemplificar, lembrei de uma situação. No curso de menor aprendiz da empresa da qual trabalhava uma colega me disse "nossa, hj meu cabelo acordou ruim, tá duro, igual cabelo de preto" daí eu respondi "engraçado, não sabia que na hora de nascer branco e preto nasciam com outra coisa na cabeça que não fosse um bastão de queratina”. Então 
assim, me ajudou muito em minha própria defesa pessoal, e em momentos posteriores a incentivar amigas que queriam passar pela transição a ter um encorajamento. E agora na faculdade eu pude compartilhar um pouco desse conhecimento com alguns coletivos e movimentos negros, onde utilizamos nosso cabelo como uma ferramenta de resistência também.

O enunciado evidencia a necessidade, frente às vivências cotidianas relativas ao racismo, de um posicionamento de "defesa" e que trouxesse "ferramentas de resistência". Assim, os processos de construção de conceitos científicos não estão alijados do contexto de assimetrias e injustiças em que está inserida a aluna. Neste ponto, partimos da perspectiva sócio-histórica-cultural para pensarmos nossa realidade latino-americana sob a ótica da Modernidade colonial que embasa o racismo estrutural e que mantém desigualdades como base para as relações de poder.

É a partir do contexto de luta e resistência social que o processo de significação de conceitos científicos se inicia. De acordo com Leontiev (1983), "a significação é a forma em que um determinado homem chega a dominar a experiência da humanidade, refletida e generalizada” (p. 225, tradução nossa). A significação, diferente do sentido, que é pessoal, reflete a experiência humana cristalizada. O conjunto das representações de uma sociedade dada.

Para saber mais sobre o processo de significação por parte da aluna, o entrevistador a questionou sobre os aspectos que ela recorda ter apreendido com a aula, explicitando, na pergunta, que gostaria de saber sobre os conteúdos de Química que foram aprendidos e utilizados no posicionamento da questão "cabelo ruim/cabelo bom".

Lembro de ter aprendido que nosso cabelo é formado pela proteína queratina, e dentre os aminoácidos que formam essa proteína há em um deles, enxofre, que vai se ligando e formando "pontes", são essas as pontes de dissulfeto. Quando mais ligações há, mais crespo o cabelo é. Ou seja, a única coisa que muda de um cabelo para o outro é a quantidade de pontes de dissulfeto.

Considerando a produção de conhecimento como parte da experiência da humanidade, e a produção de conceitos como parte da produção de conhecimento, aquilo que o sujeito pensa ou compreende sobre determinado conceito pode não coincidir exatamente com a sua significação. Assim, o conceito de proteína ou de ponte de dissulfeto, para a aluna, poderia não coincidir com seu significado dado pela ciência. No entanto, mesmo em meio aos sentidos pessoais atribuídos à atividade, ela expressou coincidência entre o sentido e o significado dos conceitos químicos, ou melhor, do sistema de conceitos químicos já cristalizados na ciência, expressos na resposta. Em outras palavras, assiste-se à superação do sentido pessoal de seu posicionamento para a construção de significado dos conceitos da Química. Consideramos que o sentido, ao interagir com o significado, seja um elemento determinante da significação para a apropriação dos conceitos.

O conceito de apropriação, dentro do referencial teórico adotado, é compreendido como sendo o processo por meio do qual o sujeito "reproduz em si as formas histórico- 
sociais da atividade" (Davidov, 1988 citado em Moretti, \& Moura, 2011, p. 11). Considerando a atividade de estudo, a aluna expressou uma explicação que implica a reprodução de relações entre objetos de estudo pertencentes à escala submicroscópica, macroscópica e social, ou seja, operou com o conceito em diferentes escalas contextuais, que fazem parte da sua realidade sócio-histórico-cultural.

A explicação da aluna reflete um movimento semelhante ao da mediação do professor na condução da atividade proposta em aula, e, portanto, ao da própria dinâmica da atividade: partindo-se da aparência do concreto imediato e suas consequências sociais, dirigindo-se à essência do objeto por meio do estudo dos conceitos da Química e retornando ao concreto, agora complexificado; a aluna também iniciou se referindo ao cabelo, percorrendo o sistema de conceitos de sua composição química, que embasa a justificativa do seu posicionamento frente aos julgamentos da aparência do cabelo como questão social.

Isso nos sugere um indicativo de que o caminho mediacional de como os conceitos são trabalhados reflete-se no modo como o aluno se apropria do sistema de conceitos e, consequentemente, como exterioriza esta apropriação. Portanto, não serão definições teóricas estanques de conceitos científicos alheios à realidade do aluno que contribuirão para uma apropriação e significação do conhecimento produzido pela humanidade, mas sim a atividade de práxis reproduzida na atividade de ensino-aprendizagem, de maneira que o sujeito transforme sua realidade pela tomada de consciência.

\section{O uso de conceitos em outros contextos pelo aprendiz: o movimento de generalização em contexto de desigualdades}

Os dados que subsidiaram a discussão sobre o uso de conceitos químicos por parte da estudante, em outros contextos sociais, foram analisados a partir do enunciado que ela produziu frente à pergunta sobre a mobilização dos conceitos apreendidos após um ano da realização da atividade.

Eu consegui fazer links dos conceitos em outras aulas do "nome do curso", e inclusive na escola onde cursava o ensino médio, onde me dei muito bem em química orgânica, por ser algo que eu tinha muito interesse em estudar e participar das aulas. Acho que em geral, os conceitos visto naquela aula em específico me deram um "empurrão" para me interessar sobre outros assuntos semelhantes. Então, eu sempre me pegava lendo composição de remédios e procurando entender seus componentes, como funcionavam, e não só isso, mas procurando a química em outras coisas também. Antes disso, eu não gostava muito de química, já tinha procurado entender, mas achava difícil. Daí quando eu passei a enxergar a química no dia a dia, eu passei a compreendê-la melhor, um pouquinho que fosse. E isso claro, me ajudou muito no vestibular também.

Os usos dos conceitos químicos na vida da aluna incluem outras aulas do projeto, a escola, o vestibular, o cotidiano, e os benefícios trazidos com isso. Podemos, então, inferir que a aprendizagem foi efetiva na medida em que atendeu às necessidades envolvidas nesses outros cenários. 
Percebe-se, por isso, uma mudança na forma de atribuir sentidos à disciplina de Química. Afinal, parte-se de um estado no qual a aluna "não gostava", "achava difícil", e chega-se a um estado expresso por "me interessar" e "compreendê-la melhor, um pouquinho que fosse". Dessa forma, a atividade de estudo forneceu instrumentos (conceitos) que complexificaram contextos escolares anteriores e motivaram posteriores. Colaborou também na busca por conhecimentos presentes no cotidiano aluna e na significação social da disciplina de Química.

$O$ processo de significação sobre a relação entre a atividade e os conceitos químicos pôde ser aprofundado no momento em que o entrevistador perguntou se ela considerava a aula vivenciada como uma aula de Química, pedindo que justificasse o motivo.

Sim, eu considero a aula como sendo uma aula de química. Pois, os conhecimentos adquiridos nela não me serviram apenas para responder questões a respeito do cabelo e suas texturas, mas sim para assimilar outros questionamentos. Como por exemplo, pode fazer um link dessa aula com uma aula ministrada por outro professor, onde vimos o sistema digestivo, e novamente entrei em contato com proteínas, no caso, quando estávamos falando sobre a ação da pepsina. Ou seja, a química esteve presente tanto numa aula onde estudamos e debatemos um problema de cunho social, quanto em uma aula onde foi estudado um processo do corpo humano.

Como o objetivo da aula foi o ensino-aprendizagem de conceitos da Química por meio de uma questão sociocientífica controversa de caráter étnico-racial, a aluna reconhece a utilidade da Química.

Aqui também se observa a transição do conceito de proteína entre estruturas de generalidade, se considerarmos como estruturas de generalidade o sistema de conceitos no contexto do sistema digestivo e o sistema de conceitos no contexto da questão étnicoracial. Segundo Vigotski (2009), o desenvolvimento do conceito se dá, em termos psicológicos, em meio a um sistema de estruturas de generalizações a partir de relações de generalidade entre conceitos, em que "a essência de seu desenvolvimento é, em primeiro lugar, a transição de uma estrutura de generalização à outra” (p. 246). Se considerarmos as escalas macro, submicro e social como estruturas de generalização nas quais os conceitos referentes aos respectivos objetos de estudo precisam realizar transições/ relações de generalidade deliberados pelo aluno, podemos perceber o movimento de transição dos conceitos utilizados pela aluna entre as estruturas de generalizações como a exteriorização do estágio de desenvolvimento/formação no qual se encontram seus conceitos no momento da presente entrevista.

A grosso modo, pudemos identificar pelo discurso da entrevistada o uso de um mesmo conceito em diferentes contextos, corroborando para a significação, apropriação e generalização, enfim, para a formação do conceito de proteína e do sistema de conceitos que o contém. Isso em diferentes momentos do processo de formação da aluna ao longo do ano em que esteve conosco, caracterizando um processo sócio-histórico. 


\section{Relações ensino e aprendizagem após a vivência da atividade: superação das contradições e tomada de consciência}

O conjunto de vivências da aluna, em uma proposta de ensino e aprendizagem que parte de temas reais, urgentes e emergentes de seu contexto sócio-histórico-cultural, é uma premissa da presente pesquisa. Assim, caminhando para o fim da entrevista, a aluna foi inquirida sobre como tal atividade influenciou sua forma de pensar a metodologia educacional vivenciada no projeto de Educação Popular, e quais princípios a estudante levou para sua carreira acadêmica após um ano na Universidade.

Bom, pensando nas aulas do "Conexão", uma das coisas que me ajudou muito com os estudos foi a aproximação com o dia a dia mesmo. As coisas faziam sentido pra mim, e isso era o que me instigava a procurar saber. Eu nunca gostei de disciplinas que exigissem raciocínio lógico, vulgo exatas. Mas por exemplo, me vi querendo saber sobre como funciona o diagrama de Venn, ou como calcular o volume de uma caixa d'água. Porque eu tive curiosidade, curiosidade de saber o que iria acontecer, qual seria o resultado. Uma das coisas que me ajudou muito também foi a autonomia. Isso na verdade eu só pude perceber depois que saí do projeto e entrei na faculdade. Diversas vezes nas aulas você e os outros professores colocavam questionamentos pra gente e não nos dava resposta, mas pedia que nós mesmos fossemos atrás destas. E confesso que na época achava isso chato, eu queria as respostas na hora. Já aproveitando para falar sobre a carreira acadêmica, isso é algo que fez grande diferença, essa autonomia. Os professores dão muitas referências boas, e cabe a nós, discentes ir atrás, saber filtrar o que realmente vale a pena, ler, procurar, estudar. E vejo que não é o que ocorre com grande parte dos alunos. O curso em que estou, no campus em que estou, tem uma certa fama de "passar todo mundo", de não ser muito rigoroso em relação às notas, e etc. Eu na verdade, vejo isso de modo diferente, e acredito que isso venha do "nome do curso". Os professores aqui não dão muitas provas e não se preocupam muito com notas, mas sim com maneiras de ensinar que sejam ativas, que nos faça agir, ou melhor, interagir. Tive algumas disciplinas em que foi proposto para que nós alunos formassem grupos, e a partir daí nós trabalhamos em cima de alguns temas. O grupo como um conjunto teve de pesquisar assuntos em plataformas, revistas, e etc de artigos científicos e montar uma aula expositiva para os outros alunos. E além disso, cada grupo teve de elaborar algumas perguntas para os outros responderem também. Foi muito legal e dinâmico, porém vários colegas se indignaram, alegando que isso era preguiça do professor dar aula, sendo que o mesmo estava o tempo todo à disposição para ajuda, muitos também tiveram dificuldades para procurar os artigos, trazer informações completas. Os docentes comentaram o fato de ter muita coisa do senso comum, pois muita gente não sabia procurar as informações. E com certeza, isso que o "Conexão" me proporcionou me ajudou muito nas aulas, e também está me ajudando em uns futuros projetos de iniciação que estou pensando.

Não se trata de uma questão sobre a aula, mas sobre o projeto de Educação Popular como um espaço-tempo de formação do qual a aluna participou durante um ano. 
A aluna destacou novamente que a relação feita entre os conhecimentos trabalhados em aula e o seu cotidiano fez sentido para ela e a motivou a estudar conceitos que antes não tinha interesse. O que nos reitera a importância da aproximação dos temas planejados para a aula com a realidade do aluno, salientando que não se trata de qualquer cotidiano, mas da realidade sócio-histórico-cultural dos alunos. Percebe-se, novamente, que a relação com o cotidiano promove uma mudança no sentido atribuído aos conhecimentos da área de exatas. Antes, um desgosto, depois, curiosidade. Salientamos, também, como professores desse projeto, que buscamos o tratamento da realidade do aluno não como mera aplicação de exemplos pontuais. $\mathrm{O}$ modo como trabalhamos a realidade é uma busca constante em nossa atividade de ensino-aprendizagem, com o auxílio de teorias e princípios educacionais que possam vir a atender esta necessidade, e que formem e reformem constantemente o professor pesquisador, como é o caso da pesquisa aqui compartilhada.

Consideramos que, assim como a curiosidade por conhecimentos não diretamente relacionados à sua área acadêmica, também o desenvolvimento da autonomia, apontado pela aluna, são parte integrante de sua transformação e libertação como sujeito sóciohistórico-cultural ativo e crítico.

O entrevistador, nos momentos finais da entrevista, abriu espaço para que a aluna pudesse acrescentar algo que não foi questionado, ou sobre o que não conversaram durante a entrevista. Neste momento, a aluna evidenciou o reconhecimento dos processos de mediação e a importância de uma relação de ensino e aprendizagem não desconectadas das questões políticas e existenciais, abordagem própria da Educação Popular.

Eu só gostaria de deixar o meu agradecimento à todos os professores do “Conexão”. Essa aula teve/tem um valor muito grande pra mim. Eu pude descobrir não só conteúdos de algumas disciplinas, mas coisas mais profundas sobre mim. Então, agradeço ao projeto por me proporcionar uma experiência de aula tão incrível, de uma maneira que eu jamais esperei, e que com certeza eu levarei todas as experiências nela vivida pelo longo da carreira.

Quando a aluna explicitou que pôde descobrir "não só conteúdos [...] mas coisas profundas sobre mim", sugere que os conteúdos não são a coisa mais importante da aula, mas o sentido pessoal experienciado. Sabemos que os sentidos pessoais estão mais profundamente arraigados no psíquico do sujeito, construídos historicamente por mediações sociais e culturais (Vigotski, 2009). Para Moretti e Moura (2011), "o sentido pessoal está sempre ligado ao motivo que incita o sujeito a agir", o que nos mostra que, se conseguirmos, como educadores, atingir sentidos pessoais dos alunos ao trabalhar sua realidade, o ensino-aprendizagem irá se tornar uma experiência transformadora do sujeito.

Sabemos que é impossível atingir o sentido pessoal de todos os alunos de uma sala de aula ao mesmo tempo. Dessa forma, deve ser considerado, numa classe heterogênea, o levantamento de falas significativas e a variabilidade de temas, estímulos e modos de mediações. 


\section{Conclusões e implicações}

Partindo das propostas da Educação Popular, é iminente a preocupação em diminuir assimetrias sócio-históricas que oprimem e anulam os sujeitos que compõem minorias no que tange aos acessos e direitos. Abordar questões que revelam aspectos positivos das relações étnico-raciais, tais como a dimensão estética, permite um ensino de ciência inclusivo, que faça com que a juventude negra, neste caso, sinta-se contemplada nos processos de ensino e aprendizagem.

A partir do que foi até aqui apontado, retomamos as perguntas de pesquisa, presentes no início deste artigo, a fim de apresentarmos ao leitor maior detalhamento conclusivo.

Primeiramente, perguntamos de que maneira ocorre a apropriação de conceitos científicos a partir de uma atividade de estudo constituída por uma questão étnicoracial?

À guisa de resposta, ressaltamos que a análise do relato de uma aula, cujo principal intuito foi promover diálogos entre os diferentes saberes, que possibilitaram instaurar em classe a controvérsia estética da questão étnico-racial, revelou aspectos significativos sobre a apropriação de conceitos relacionados ao mundo submicroscópico. Notou-se que o engajamento frente a questões agudas da sociedade promoveu a mobilização dos conceitos como forma de dar mais força ao argumento produzido.

É importante ressaltar o papel da mediação do professor, tendo ele se envolvido nas hipóteses iniciais e respaldado a mediação de elementos do campo científico; partindo-se do concreto sensório, ligado ao estigma do "cabelo ruim" - vivenciado cotidianamente pelos alunos - e direcionando-se para o abstrato submicroscópico dos conceitos químicos, úteis para se entender e refutar a concepção primeira. Para isso, o docente auxiliou os alunos no reconhecimento e domínio das generalizações entre os contextos macro e micro de sua realidade, fazendo com que a aprendizagem de conceitos abstratos não tivesse um fim em si mesma.

A entrevista nos revelou, com maior profundidade, as transformações na realidade sócio-histórico-cultural da aluna entrevistada, apontando para a possibilidade de educadores, na medida em que tomam o contexto de seus alunos, proporem atividades de práxis que os motivem a buscar o conhecimento científico.

Posteriormente, a pergunta feita foi: Como as dimensões estética, ética e política associadas a primeira questão aparecem na atividade de estudo desenvolvida?

A questão étnico-racial, posta em uma dimensão estética, evocou a contra palavra como ato político, promovendo reflexões também de contornos éticos. A necessidade de posicionamento perante a motivação (preconceito) coincidiu com a busca pelo conhecimento científico/químico (objeto), caracterizando a atividade de estudo. Neste movimento de busca de conhecimento e posicionamento, significações, apropriações e generalizações de conceitos químicos são parte do processo de formação de conceitos e transformação da realidade do sujeito que, no caso da entrevistada, qualificamos como transformação libertadora. 
Tomando como ponto de partida um enunciado controverso e emergente do cotidiano dos estudantes, identificou-se, pelo relato do professor, posicionamentos híbridos entre elementos linguísticos do campo das tecnociências e elementos do conhecimento cotidiano que delinearam as situações-limite ${ }^{7}$ dos participantes da atividade de estudo. Ao longo das discussões mediadas, houve a complexificação das relações entre a cultura científica escolarizada, nomeadamente àquelas relacionadas ao conhecimento químico, e os aspectos do conhecimento cotidiano que desafiavam o lugar enunciativo daqueles que se sentiam tocados pelas questões identitárias da dimensão estética das questões étnico-raciais.

Apontamos, ainda, para a demanda por outras pesquisas que evidenciem o processo de ensino-aprendizagem a partir de sua multidimensionalidade (Candau, 2014). Em outras palavras, que não se considerem apenas os aspectos didáticos, mas também os políticos, sociais, históricos e culturais da realidade diversa e multicultural do contexto brasileiro, marcado por intensas assimetrias socioeconômicas vivenciadas pelos sujeitos aprendizes.

Por fim, as limitações deste trabalho apresentam-se na medida em que consideramos a construção de conceitos científicos escolares no contexto da psicologia social, mas que não contemplam as possibilidades de diálogos interculturais com dimensões do conhecimento afro-brasileiro de forma mais aprofundada. Pretendemos, em futuros trabalhos, avançar em propostas que considerem a pluralidade epistêmica e abordagens culturais entre as ciências que permeiam a cultura escolar e as culturas afrobrasileiras, de forma a estabelecer pontes dialógicas que aprofundem essa construção positiva e que fortaleça o combate ao racismo estrutural que assola nossa sociedade.

\section{Agradecimentos}

À CAPES, pelo fomento; ao grupo Conexão por tornar o processo possível.

\section{Referências}

Aikenhead, G. S. (1994). What is STS science teaching? In J., Solomon, \& G., Ainkenhead, STS education: international perspectives and reform. New York: Teachers College Press, 47-59.

Aikenhead, G. S. (2009). Educação científica para todos. Tradução de Maria Teresa Oliveira. Portugal: Edições Pedagogo.

\footnotetext{
7 Elemento da investigação temática Freireana (Freire, 1987) que expressa a tomada de consciência das situações significativas e contraditórias vivenciadas pelos sujeitos. Segundo Brick, Pernambuco, Silva e Delizoicov (2014), envolve a análise e a escolha das situações contraditórias a serem codificadas (imagens, falas etc.), de forma que sejam reconhecíveis pelos sujeitos e que, nelas, eles possam se reconhecer, e que seu núcleo não seja nem tão explícito e nem muito enigmático, propiciando a próxima etapa, que se inicia após preparadas as codificações e o estudo de todos os ângulos temáticos pela equipe interdisciplinar.
} 
Brick, E. M., Pernambuco, M. M. C. A., Silva, A. F. G., \& Delizoicov, D. (2014). Paulo Freire: interfaces entre Ensino de Ciências Naturais e Educação do Campo. In M. C. D. A., Molina, (Org.). Licenciaturas em Educação do Campo e o Ensino de Ciências Naturais: desafios à promoção do Trabalho Docente Interdisciplinar. Brasília: NEAD, 267p.

Camillo, J., \& Mattos, C. (2014). Educação em ciências e a teoria da atividade culturalhistórica: contribuições para a reflexão sobre tensões na prática educativa. Revista Ensaio. Belo Horizonte, 16(1), p. 211-230.

Candau, V. M. (2014). A didática e a formação de educadores - da exaltação à negação: a busca da relevância. In Candau, V. M. (org.). Didática em questão. (36a ed.). Petrópolis, RJ: Vozes.

Candela, A. A.(1999). Ciencia en aula: los alumnos entre la argumentación y el consenso. México: Paidós.

Davidov, V., \& Markova, A. (1987). La concepcion de la actividad de estudio de los escolares In V., Davidov, \& M., Shuare, La psicología evolutiva y pedagogía en la URSS: antología. Moscú: Editorial Progreso, p. 316-336.

Driver, R., Asokoh Leach, J., Mortimer, E., \& Scott, P. (1999). Construindo o conhecimento científico em sala de aula. Tradução de Eduardo Fleury Mortimer. Química Nova na Escola, 9.

Fraser, M. T. D., \& Gondim, S. M. G. (2004). Da fala do outro ao texto negociado: discussões sobre a entrevista na pesquisa qualitativa. Paidéia, Ribeirão Preto, 14(28), p. 139-152. http://dx.doi.org/10.1590/S0103-863X2004000200004.

Freire, P. (1967). Educação como Prática da Liberdade. Rio de Janeiro: Paz e Terra.

Freire, P. (1987). Pedagogia do oprimido. (17a ed.). Rio de Janeiro: Paz e Terra. 107 p.

Gadotti, M. (2012). Educação popular, educação social, educação comunitária. In Congresso Internacional de Pedagogia Social, n. 1, São Paulo, 2012. Anais do Congresso Internacional de Pedagogia Social. São Paulo: USP.

Gilbert, J. K., Boulter, C. J., \& Elmer, R. (2000). Positioning Models in Science Education and in Design and Technology Education. In J. K., Gilbert, \& C. J., Boulter, (Eds.), Developing Models in Science Education. Dordrecht: Kluwer, 3-17. Recuperado de https://doi.org/10.1007/978-94-010-0876-1_1.

Grossi, F. V. (1984). Popular education: Latin American experience. International Review of Education, 30, 303-314. https://doi.org/10.1007/BF00597907.

Jara, O. (2010). Educación popular y cambio social en America Latina. Community Development Journal, Oxford, 45(3).

Kato, D.S. (2011). O papel dos cursinhos populares nos acessose mudanças de perspectivas de seus participantes. Cadernos CIMEAC, 1, p. 5-24, https://doi.org/10.18554/cimeac. v1i1.1430. 
Lei no 10.639, de 9 de janeiro de 2003. Altera a Lei no 9.394, de 20 de dezembro de 1996, que estabelece as diretrizes e bases da educação nacional, para incluir no currículo oficial da Rede de Ensino a obrigatoriedade da temática "História e Cultura Afro-Brasileira", e dá outras providências. Diário Oficial [da] República Federativa do Brasil. Brasília, DF, 10 jan. 2003. Recuperado de http://www.planalto.gov.br/ccivil_03/Leis/2003/L10.639. htm.

Leontiev, A. N. (1978). O desenvolvimento do psiquismo. São Paulo: Moraes.

Leontiev, A. N. (1983). Actividad, conciencia, personalidad. (2a ed.). Havana: Pueblo y Educacion.

Moretti, V. D., \& Moura, M. O. de. (2011). Professores de matemática em atividade de ensino: contribuições da perspectiva histórico-cultural para a formação docente. Ciência \& Educação (Bauru), 17(2). 435-450. https://dx.doi.org/10.1590/S151673132011000200012 .

Munanga, K., \& Gomes, N. L. (Orgs). (2006). O negro no Brasil de hoje. São Paulo: Global. (Coleção para entender).

Narita, F. Z. (2014). Temas, conceitos e processos em Educação Popular: uma discussão a partir das ciências sociais. Cadernos CIMEAC, 4(2). 41-57. https://doi.org/10.18554/ cimeac.v4i2.1467.

Parecer CNE/CP n. ${ }^{\circ}$ 3, de 10 de março de 2004: Diretrizes Curriculares Nacionais para a Educação das Relações Étnico-Raciais e para o Ensino de História e Cultura Afro-Brasileira e Africana. Conselho Nacional de Educação, Ministério da Educação, Brasília. Recuperado de http://portal.mec.gov.br/cne(a)rquivos/pdf/003. pdf.

Pedretti, E. (2003). Teaching science, technology, society and environment (STSE) education: preservice teachers' philosophical and pedagogical landscapes. In Zeidler, D. L. (Org.). The role of moral reasoning on socioscientific issues and discourse in science education. Nederlands: Kluwer Academic Publishers, 219-239.

Sadler, T. D., Amirshokoohi, A., Kazempour, M., \& Allspaw, K. M. (2006). Socioscience and Ethics in Science Classrooms: Teacher Perspectives and Strategies. Journal of Research in Science Teaching, 43,353-376. https://doi.org/10.1002/tea.20142.

Santos, W. L. P. (2007). Contextualização no Ensino de Ciências por meio de temas CTS em uma perspectiva crítica. Ciência \& Ensino, 1(especial).

Verrangia, D. (2014). Educação Científica e Diversidade Étnico-Racial: O Ensino e a Pesquisa em Foco. Interacções, 31, 02-27.

Vigotski, L. S. (2007). A formação social da mente. São Paulo: Martins Fontes.

Vigotski, L. S. (2009). A construção do pensamento e da linguagem. (2a ed.). São Paulo: Martins Fontes. 
Wartha, E. J., \& Rezende, D. B (2011). Os níveis de representação no Ensino de Química e as categorias da semiótica de Pierce. Investigações em Ensino de Ciências, 16(2,) p. 275-290.

Danilo Seithi Kato

(1) https://orcid.org/0000-0003-3065-6812 Universidade Federal do Triângulo Mineiro Uberaba, Minas Gerais, Brasil danilo.kato@uftm.edu.br

Beatriz Vivian Schneider-Felicio

${ }^{0}$ https://orcid.org/0000-0002-7080-9222 Universidade de São Paulo Programa de Pós-Graduação Interunidades em Ensino de Ciências São Paulo, São Paulo, Brasil biavss23@usp.br

Submetido em 10 de abril de 2019

Aceito em 28 de outubro de 2019

Publicado em 20 de novembro de 2019 